\title{
Developing multidisciplinary blended learning courses for maritime education with cross-European collaboration
}

\author{
Evangelos Boulougouris ${ }^{1}$ (D) Panagiotis Mizythras ${ }^{1} \cdot$ Leonidas Chrysinas $^{2}$. \\ Georgios Vavourakis ${ }^{2}$ - Gerasimos Theotokatos ${ }^{1}$ - Murat Aymelek ${ }^{3,4}$. \\ Ismail Kurt ${ }^{3}$
}

Received: 13 April 2018 / Accepted: 4 March 2019 / Published online: 21 March 2019

(C) The Author(s) 2019

\begin{abstract}
Continuous training is considered nowadays as a key issue for the evolution of people being at professional and personal levels, enhancing productivity, employability, and social stability in a globally competitive world. Furthermore, the introduction of new technologies, the imposition of new regulations in the maritime industry and the growing challenges at port, shipping and logistics level increase the demand for new educational schemes. Concerning the market needs, TrainMoS II and On the MoSway Network (OTMW-N) European projects aimed for the development of student and professional's skills and laid the foundations for a cross-European maritime educational programme. TrainMoS II was the evolution of the TrainMoS project, improving the existing tools and covering a whole new range of technical and operational topics, including alternative fuels and technologies, logistics and safety issues such as damage control, evacuation and crisis management operations. TrainMoS II covered also the provision of blended vocational education to undergraduates and professionals who belong to different sectors in the multimodal transport chain. Both projects focused on the establishment of an educational framework facilitating the collaboration between industry and academia and used advanced ICT tools to match the maritime market needs with the training provision and to develop new and enriched content for the online platform with learning material and knowledge for both professionals and students. In the present study, the outcomes and experiences gathered from running the aforementioned projects are presented and discussed for their potential impact on the maritime industry.
\end{abstract}

Keywords Vocational education · Alternative fuels · Maritime industry · Training schemes · Motorways of the seas $\cdot$ Blended learning $\cdot$ e-learning $\cdot$ Multimodal transport chain

Evangelos Boulougouris

evangelos.boulougouris@strath.ac.uk

Extended author information available on the last page of the article 


\section{Introduction}

The maritime transport industry is highly competitive and continuously evolving, adapting to an increasingly dynamic, complex and information-driven business world. Knowledge and contemporary information are invaluable assets for achieving sustainable growth (Grewal and Haugstetter 2007) affording a competitive advantage to those who possess it and an enabler to those who can provide it. In our fast developing world, knowledge and information may become outdated or irrelevant very quickly. This necessitates lifelong learning which should cover both postgraduate and vocational education and should inspire practitioners to pursue postgraduate maritime degrees, capable of preparing and re-training maritime professions ( $\mathrm{Ng}$ et al. 2009). European policymakers understood the importance of the human element and introduced it as a critical element into the Trans-European Transport Networks (TEN-T) programme for the development of the Motorways of the Sea (MoS) (Commission of the European Communities 2011).

When it comes to the vocational education pillar, the Copenhagen Declaration (European Commission 2002) was the first official document revealing the importance of closer cooperation between European countries for the further development of vocational education and training (VET). VET programmes are considered as unique tools for promoting the employability and the economic growth. They enhance also the cohesion within regional and European societies for a sustainable growth. Furthermore, the education is characterised as one of the main pillars of the Blue Economy business model leading to a green economy and increasing productivity (Bruges Communiqué 2010). However, OECD studies illustrate a low implementation of vocational training at the post-secondary educational level in the European Union (EU) relative to the potential demand (OECD 2014). The results of these studies were confirmed from surveys performed in various European regions, indicating that there are great discrepancies in VET programmes and policies (IBCVET 2017).

The main post-secondary vocational programmes are the modern apprenticeships, which include industry designed programmes that support employees to acquire certificated competencies. The key practise of these programmes is to deliver their knowledge through work-based learning and/or off-the-job training. This approach is limited within business and does not allow the knowledge dissemination to other sectors. Other programmes, provided mainly in colleges, are the higher national certificates (HNC) and higher national diplomas (HND), which offer a mix of practical skills and theoretical knowledge in their job-related courses, allowing progression onto a degree programme (OECD 2013). In addition to these, a huge number of seminars and conferences related to the maritime sector take place every year in the majority of European countries. Most of them aim to present the companies' work during the last period, advertising their achievements and communicating the forthcoming steps. As a result, the educational purposes of these schemes have lower priority than the companies' reputation and network development.

The Sorbonne and Bologna Declarations (Ministerial Declaration 1998, 1999) introduced the development of a European Higher Education Area (EHEA), reforming and setting the fundamental principles of the European educational system. Continuing the key commitments that were established in these declarations, the Bologna followup group has decided to support an EHEA focusing on the strengthening of the three- 
cycle degree educational structures and the improvement of the quality assurance and qualification recognition in respect of employability and society values (European Commission 2018a).

However, there is a wide range of employees who are occupied in the maritime sector with limited access to the industry evolution, the advances of technology and the alterations of policy framework. Simultaneously, the challenge to improve the quality of the delivered products and services increases the growing demand for properly trained and skilled people in the maritime industry. The only feasible way to achieve their goal, to maintain their usefulness and to improve their skills is through training. Training schemes can be theoretical or practical. According to Aristotle (384-322 B.C.): Both theoretical and practical wisdom are essential for bringing people to eudemonia (i.e. happiness or flourishing or living well) (Ross and Brown 2009). Apart from 'eudemonia', both theoretical and practical training are important elements to successfully implement the state of the art in their own position and to significantly contribute to the maintenance of each company's competitiveness in the race of evolution. The development at this educational level can be carried out by specialised training centres and from people with specific integrated skills and knowledge. Unluckily, though the challenges are common across the Europe, the current competences and expertise are most of the time regional and limited.

Besides the importance of education in society, the limited availability on time and knowledge resources at the regional level are the commonest obstacles in the training process. In the last decade, these challenges have been overcome with distance learning. Distance learning has a long history starting in its first generation with courses of instruction delivered by mail, up to today's 5th generation using the Internet and the Web (Moore and Kearsley 2012). This latest generation allows the virtual training of learners and it can be achieved by using personal computer networks, utilising software that permits the clear transfer of sound and image between different places. Through distance learning, every individual has the opportunity to actively participate in classes from different areas, making questions, taking part in possible experiments or simulation processes. This fact was also captured by the European Commission (EC) which provided extra motivations and funding for training projects that support distance learning such as TrainMoS II (www.trainmos2.eu) and On the MoSway Network (OTMW-N, www.onthemosway.eu/onthemoswaynetwork/) which are presented herein. As a result, any professional or student who meets the prerequisites of the training programme may participate in these blended learning modules, without regional boundaries.

\section{Background}

\subsection{Module design}

The objective of any course is to provide the best learning experience to the students. In learning theory, four main orientations are identified according to Merriam and Caffarella (1998): the behaviourist; the cognitive; the humanistic; and the social/ situational. The approach selected for the development of the courses in the project presented herein was mainly the cognitive one, as the purpose of the education was to 
develop capacity and skills. Even though some elements of the behaviourist orientation were included in the courses, as one of the intentions was to change the behaviour of the students towards specific key, new themes such as the use of alternative fuels (especially LNG) and policies such as the EC's Single Window Directive (EC 2010c).

Focusing on the cognitive orientation of the modules, we see that Bloom (1956) introduced the Taxonomy of Educational Objectives, providing carefully defined categories for the six major aspects of the cognitive process. These were knowledge, comprehension, application, analysis, synthesis and evaluation. Bloom analysed them further to a number of subcategories. This taxonomy had a cumulative hierarchy as each simpler category was prerequisite to mastery of the next more complex one (Krathwohl 2002). It was later revised by Krathwohl et al. (1964), renaming three categories, changing all their names to the verb form (i.e. remember, understand, apply, analyse, evaluate, create) and introducing various kinds of knowledge as a second dimension. Depending on the complexity of the kind of knowledge, Krathwohl suggested the classification to factual, conceptual, procedural and metacognitive knowledge, creating the taxonomy table (Krathwohl 2002). With its help, the objectives, activities and assessments of a course or a module can be classified in a clear and concise way that is easy to communicate. Middendorf and Pace (2004) argue that in the last few decades, the challenge for academia is to push the students to the higher levels of Bloom's learning behaviours classification.

Shulman (2005) suggests that the learning process in particular contexts, created by specific disciplines, has unique characteristics and he introduces the term signature pedagogies in order to define them. He notes that in these signature pedagogies, the novices are instructed in critical aspects of what he considers the three fundamental dimensions of professional work, i.e. to think, to perform and to act with integrity. He suggests also that professional pedagogies have more challenges as they must measure up to the standards of the profession, not only those of the academy.

Romiszowski (1981) agrees too that professional education requires an alternative approach. Bloom and Krathwohl's taxonomies do not distinguish between knowledge and skill. That is why Carter (1985) proposes another division when it comes to professional training, introducing skill learning and personal qualities (affective learning) next to knowledge. The skills can be information, mental, action or social, whereas the personal qualities can be categorised in mental characteristics, attitudes and values, personality characteristics and spiritual qualities. Therefore, the taxonomy of objectives for professional education proposed by Carter is shown in Table 1.

The devolution from secondary education to professional domain, or further education, has been characterised as chaotic (National Institute on Post-Secondary Education 2000). The main reasons of this problematic connection are the lack of discussion involved in institutional processes, the motives acceptance deficiency, the opaque usage of language with complicated terms and the individuals' ignorance in more complex aspects of processes (Haggis 2009). In this concept, the only way to obtain the respective proper technique is the establishment of flexible educational and continuous training schemes using visual sources of data to advance the knowledge (Fischman 2000) and deep understanding of the individual (Haggis 2009). Furthermore, the EHEA is regarded as a public infrastructure for entrepreneurial higher education according to Simons (2008), using the knowledge as an investment for a better future. The combination of training and research through universities leads to the University 
Table 1 Taxonomy of objectives for professional education adopted from Carter (1985)

\begin{tabular}{|c|c|c|c|c|c|}
\hline $\begin{array}{l}\text { Personal } \\
\text { Qualities }\end{array}$ & $\begin{array}{c}\text { Mental Characteristics } \\
\text { Openness } \\
\text { Agility } \\
\text { Imagination } \\
\text { Creativity }\end{array}$ & $\begin{array}{c}\text { Attitude and Values } \\
\text { Things } \\
\text { Self } \\
\text { People } \\
\text { Groups } \\
\text { Ideas }\end{array}$ & $\begin{array}{c}\text { Personality } \\
\text { Characteristics } \\
\text { Integrity } \\
\text { Initiative } \\
\text { Industry } \\
\text { Emotional } \\
\text { resilience } \\
\end{array}$ & $\begin{array}{c}\text { Spiritual } \\
\text { Qualities } \\
\text { Appreciation } \\
\text { Response }\end{array}$ & Being \\
\hline Skill & $\begin{array}{l}\text { Mental Skills } \\
\text { Organisation } \\
\text { Analysis } \\
\text { Evaluation } \\
\text { Synthesis }\end{array}$ & $\begin{array}{l}\text { Information Skills } \\
\text { Acquisition } \\
\text { Recording } \\
\text { Remembering } \\
\text { Communication }\end{array}$ & $\begin{array}{l}\text { Action Skills } \\
\text { Manual } \\
\text { Organising } \\
\text { Decision } \\
\text { Making } \\
\text { Problem Solving } \\
\end{array}$ & $\begin{array}{l}\text { Social Skills } \\
\text { Co-operation } \\
\text { Leadership } \\
\text { Negotiation } \\
\text { and persuasion } \\
\text { Interviewing } \\
\end{array}$ & Doing \\
\hline \multirow[t]{2}{*}{ Knowledge } & \multicolumn{2}{|c|}{$\begin{array}{c}\text { Factual Knowledge } \\
\text { Facts } \\
\text { Structures } \\
\text { Procedures } \\
\text { Concepts } \\
\text { Principles }\end{array}$} & \multicolumn{2}{|c|}{$\begin{array}{c}\text { Experiential Knowledge } \\
\text { Experience } \\
\text { Internalisation } \\
\text { Generalisation } \\
\text { Abstraction }\end{array}$} & Knowing \\
\hline & & & Affec & & \\
\hline
\end{tabular}

Specialization (i.e. university specialised courses, workshops, seminars, masters etc.) that is capable of meeting the future challenges and market needs.

The maritime industry is considered as an environment that promotes the cooperation of individuals from different technical and scientific fields and knowledge levels. Although each individual can be highly educated and trained, there is always a problem for their adaptation to a field far removed from their original speciality (Tobias 1992). Moreover, the employment of well-educated and trained professionals is essential to promote the safe, efficient and environmentally friendly services and products, especially in cases of new technologies, such as the application of liquefied natural gas (LNG) as a marine fuel. At present, there is a shortage in the availability of suitably qualified personnel, whilst the established regulatory framework is still under development. There are also few educational institutions with the necessary resources and relevant knowledge to provide such training. Therefore, the training programmes should focus on the continuous update of their material and sources, adopting new ideas, market trends and future policies in their courses.

The structure of an effective educational programme should enhance and assure its quality and support the partnership by engaging students in learning and teaching (HEA 2014). Concerning the learning categorisation by Vermunt (2007) and the benefits of each method, depending on its application, the assignment-based teaching is considered more appropriate to develop knowledge and partnership, especially when the educational schemes are oriented to professionals. The reduced time that is required for teaching allows the students to have more freedom and responsibility during their study and it supports the knowledge initiative. Through the assignment-based teaching, the lecturers' role is upgraded, involving the tasks of coaching and setting students to work and participate actively in the lessons. Additionally, the selection of a multidisciplinary educational programme has been documented for its success to increase students' interest and job opportunities (Jensen et al. 2014). 
Nowadays, teaching can be delivered in various modes. The traditional face-to-face (F2F) lecturing, with the lecturer and the students being at the same time at the same place (ST-SP), has seen the rapid expansion of other modes of delivery such as different time-same place (DT-SP), same time-different place (ST-DP) and different timedifferent place (DT-DP) (Simonson et al. 2014). This became possible with the introduction of online education, which many believe is going to become a dominant mode of delivery in the future (Allen and Seaman 2014). The online courses can be provided in a synchronous or asynchronous mode, depending on whether the course is transmitted live or the learner has access whenever they choose using the Internet. A number of empirical studies have examined the quality of online courses and found that critical issues affecting the quality of online education include communication, technology, time management, pedagogy and assessment (Bassoppo-Moyo 2006; Conaway et al. 2005; Kebritchi et al. 2017; Limperos et al. 2015). A specific challenge that online courses seem to have, compared to the in-classroom ones, is the higher number of dropouts (Kebritchi et al. 2017). The learners' adherence to attend online courses is greatly affected by their self-motivation, their information technology (IT) skills related to the use of computers and the Internet, their perceptions and attitudes towards the Internet and their cultural and non-English background (Kebritchi et al. 2017). Contrariwise, online learning provides great flexibility and autonomy to the learners. Compared to the traditional in-classroom lecturing, online courses give to the learners a greater control of their learning materials. Due to that reason, the offering of blended learning (BL), which combines face-to-face course with online material, is constantly increasing (Garrison and Kanuka 2004). Porter et al. (2014) note that BL facilitates increasing enrolment, enhanced the use of physical facilities (by requiring less seat time than fully F2F courses) and enables higher student retention than fully online courses. Nevertheless, BL has the same technological challenges with the online courses; its scheduling has more constraints as it requires proper timetabling for classrooms; and the assessment of the learners has the same issues with the online one. These were the main challenges that were faced in the development of the modules presented herein too.

\subsection{The need}

The European Commission suggests training and awareness as one of the most important methods to improve the quality and the competitiveness of the transportation sector. In the last few years, the decisions taken in the European Transport Policy aimed to create a more sustainable society. The creation of an effective network of multimodal transport, integrating land, sea and inland waterway, and air transport has been recognised as an important aspect of sustainable development for the transport sector in the European Union. This new growth has to embody smartness, sustainability and inclusiveness, all key drivers of a Blue Economy. Based on these principles, the EU created the Trans-European Transport Networks (TEN-T) (European Commission 1992). The development of these networks is considered important for stimulating the competitiveness and increasing the employment in Europe, which are two important elements of the renewed 'Lisbon strategy' (European Commission 2010a), as well as the objectives of the new strategy 'Europe 2020' (European Commission 2010b).

As part of the TEN-T program, EC proposed in its Transport White Paper the development of Motorways of the Sea (MoS) as a real competitive alternative to land 
transport (Commission of the European Communities 2011). The concept of MoS aimed to extend existing networks and to introduce new intermodal maritime supply chains in Europe. The main objective of the MoS was to transfer a significant part of freight transport from road to sea. The selected sea areas to become 'Motorways of the Sea' included the Baltic, the seas of South-Western and South-eastern Europe and the sea areas of Western Europe and they are presented in Fig. 1. In parallel, the European Commission suggested the actions necessary for returning to the 1998's market share level of the transport modes by 2010 (Commission of the European Communities 2001). This objective was paving the way for a shift of balance from 2010 onwards. In this context, the Commission established the Marco Polo funding programme in June 2003, inspiring the reduction of road bottlenecks and the improvement of the environmental performance of the whole transport system by shifting freight from road transport to greener modes, such as short sea, rail and inland waterway transport (European Commission 2011). This is why the European Coordinator identified three key priorities for action (Simpson 2015):

- Environment

- Integration of maritime transport in the logistics chain

- Maritime safety, traffic management, human element/training

The need for education and training in relation to the deployment of the MoS is also clearly expressed in the Motorways of the Sea coordinator's report "...insisting on Education, Training and Lifelong-Learning: new training for the numerous professions linked to maritime transportation, logistics and operations in harbours must be implemented. This is fundamental for the provision of a good level of initial training rather than the on the job training currently used today" (De Oliveira 2013).

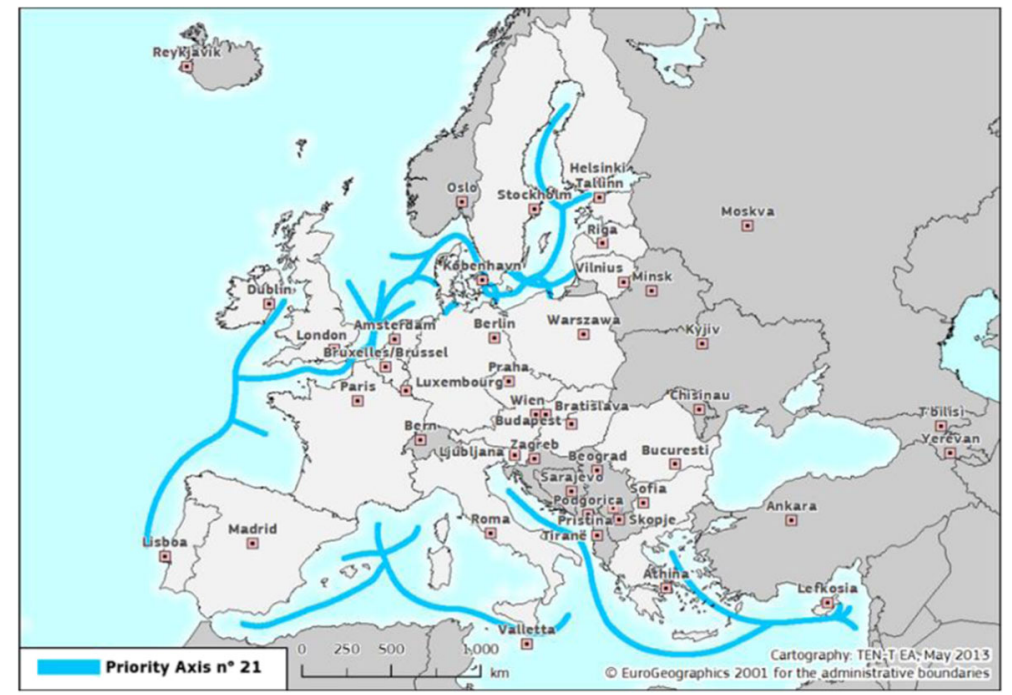

Fig. 1 Motorways of sea map (European Commission 2017) 


\section{The global project in MoS}

In this framework, a long-term Global Project (European Commission 2013) was established in MoS with the aim of creating a maritime and logistics knowledge platform, contributing to the development of an educational scheme with complete and updated contents and tools, matching the needs of the various stakeholders. The Global Project can be divided into different actions-subprojects, which address specific goals. Covering the subjects of the international economy and society, the technology evolution, or the major changes in the regulatory frameworks, several programmes should be developed under this concept to address the challenges faced by the maritime industry.

The first application of the Global Project was the TrainMoS project. The main objective of this project was the development of a MoS knowledge base, meeting the needs of the market. Utilising the EHEA, the TrainMoS action brought together universities from seven different EU Member States (Spain, Portugal, Sweden, Germany, United Kingdom, Italy, and Greece). The partners set up a full training programme on maritime and multimodal freight logistics. The project participants in combination with the universities' students created a critical mass that allowed the development and testing of a European academic module in seven MoS related subjects, which met the needs of the freight transport industry actors (European Commission 2013).

Although all the developed modules and the Learning Management System (LMS) between the collaborating universities were successfully completed by the end of 2013, the project did not reach its full potential. The main reason was its limited flexibility, as the modules were followed mainly by students of each University locally without simultaneous participation by the majority of the students during the pilot exercise. In addition, TrainMoS revealed the importance of expanding the training and include vocational education programmes to professionals, exploiting the established stakeholders' network and developing the knowledge platform that was launched and tested during that project. This paved the way for the successful application for the 'TrainMoS II' and 'On the MoSway network' (OTMW-N) projects.

The innovative aspects of these projects were the successful implementation of the blended learning to the Maritime Education and the development of the online knowledge platform in order to improve the connection between the education and the industry. Concerning the introduction of the new technologies and the limited knowledge in relation to the existing regulations and their impact to the industry, these projects focused on the development of modular educational programmes with the participation of partners with different expertise. These courses aimed to attract graduates or professionals with engineering, economics and architecture discipline background and they were working or they are eager to work in the maritime industry. Moreover, the application of modern techniques during the design of a maritime educational programme was adopted, evaluating the impact of these programmes on the professionals and the students.

\subsection{TrainMoS II project}

Based on the feedback of its predecessor, TrainMoS II was built upon the already generated knowledge and tools in order to answer to the new demands; to deliver new 
content (post-degree courses, professional training and vocational education); to improve the existing information and communication tools (ICT); and to bridge the demand and offer of training and jobs with a specific section using the 'onthemosway.eu' portal (European Commission 2018b). TrainMoS II consolidated consortium consisted of six prestigious EU Universities (University of StrathclydeUoS, University of Genoa-UniGe, Technical University of Madrid-UPM, National Technical University Athens - NTUA, University of Piraeus - UniPi and Faculdade de Ciências Sociais Humanas in Lisbon-FCSH). The consortium was completed by two IT partners (Circle S.p.A. and CIMNE) for the educational platform support, plus public and private entities (Regione Liguria, Ocean Finance and Magellan) gathering data regarding the stakeholders' needs and best domain practices.

The goal of the TrainMoS II project was the establishment of an electronic maritime and logistics knowledge platform, covering all main levels and contributing to the development of the human element with up-to-date contents and tools in order to address the various stakeholders' needs. During the TrainMoS II project, the Spontania and Fractalis LMS ICT, provided by CIMNE, were selected based on their capacity to provide or develop the necessary functionalities. Spontania is a unified group video conference and collaboration software application, which allows full range of interactive real-time communication and collaboration utilities, whilst the Fractalis LMS ICT is a software e-learning platform. The further development of the videoconference systems and portals that were introduced in TrainMoS project would allow the update and expansion of the stakeholders' database, giving a better indication of the industry needs from a maritime educational programme. Based on the electronic platforms and processing the various addressed issues, the final objective of the TrainMoS II project was the establishment of the content for a maritime educational programme, which will include a number of different modules, depending on the expertise of each participating educational body. Special attention was decided also to be given to the quality certification of the established programme, settling the arrangements that were required for the recognition and accreditation of each module.

\subsection{OTMW-N project}

The idea of the OTMW-N project was generated due to the great interest of the market and society in the application of new technologies in the shipping industry. This project aimed to the provision of valuable skills and knowledge to professionals and students regarding the usage of Liquefied Natural Gas (LNG) as marine fuel, focusing on the design of a specialised LNG-oriented VET programme (European Commission 2014). The respective consortium consisted of Higher Education Institutes (University of Strathclyde_-UoS, City Glasgow College - CoGC, University of Genoa-UniGe and World Maritime University-WMU) and two private companies (Ocean Finance and Environmental Protection Engineering S.A.) with the active contribution of La Spezia port authority and the IT assistance of Circle S.p.A.

LNG is considered as the medium-term solution for the significant reduction of $\mathrm{SO}_{x}$ and greenhouse gases (GHG) emissions. This is due to lower carbon content and completive pricing. Furthermore, a great number of marine LNG engines are built by European manufacturers. Though gas fuels use is widespread in the European continent, the poor understanding of the strengths and risks of the LNG as marine fuel 
prohibit the expansion of its use. Additionally, the limited number of ports with LNG bunkering facilities prohibits the consideration of $\mathrm{LNG}$ as a viable alternative.

In order to overcome these obstacles, both onshore and onboard personnel should be aware of the advantages and disadvantages of LNG's application as marine fuel. In addition to the IMO's requirements, the intermodal characteristics of the LNG logistics have to be realised. Up to now, LNG was mainly used as fuel onboard LNG carriers and its transfer was made mainly at dedicated LNG terminals. Furthermore, the use of LNG in ports requires a different approach in handling operations and a deep understanding from all the engaged personnel for their individual roles for the safe operation of LNG fuelled ships.

The OTMW-N project, clearly in line with the market needs, aimed to address training supporting safety issues and engage a large number of stakeholders in several ways such as clustering events, networking activities, social media and the final conference. One of the major objectives of the project was the development of comprehension of the advantages and disadvantages of using the LNG as a marine fuel. Thus, the project focused on the analysis of the different perspectives that crew onboard and port employees have, identifying the common linkage between them and developing a mutual understanding. This included the evaluation of the current following procedures and the development of a new culture in all crew members, both onboard and offshore, focusing on the safe operation of LNG fuelled ships.

\section{Project outcomes}

TrainMoS II and OTMW-N projects delivered a whole series of lectures, site visit recordings and seminars across Europe. The outcomes of this effort are quite interesting. The delivered courses assisted students to recognise the importance of a holistic and multidisciplinary approach to maritime transport sustainability and to identify and evaluate the critical factors related to environmental and social sustainability of maritime transport. Moreover, they gained basic knowledge on transport systems, maritime transport and MoS, as well as on the environmental sustainability of maritime transport. The selection of the blended learning mode allowed the effective education of the participants, triggering the students to focus on the fields according to their expertise and their interests.

\subsection{Modular educational programme design}

\subsubsection{TrainMoS II project}

The TrainMoS II project gave the opportunity to new key players who were interested in the training modules to be added. In order to identify the applicable signature pedagogies (Shulman 2005) for them, a questionnaire was shared to national stakeholders' network capturing the educational needs of the maritime market. Through it, the stakeholders provided feedback and preference regarding the main focus areas which the TrainMoS II modules should cover and their future expectations concerning the training needs of the maritime sector. Taking into consideration the stakeholders demands and students' interests, the project consortium focused on the dissemination of 
its training programmes and set as a cornerstone the establishment of a strong linkage between industry and educational institutes. Thus, 'focus groups' meetings were organised in Italy, Portugal, Spain, Greece and the UK. Notices regarding the meetings were published through the developed online platform, as well as the dissemination of each meeting outcomes (On the MoSway portal 2017). By the end of 2014, more than 130 stakeholders were involved in the meetings, identifying the important issues that should be addressed, and bringing the project scope close to the industry's needs. Simultaneously, the tasks of each activity were planned and the main topics of the training modules were prepared. The main challenges faced by the partners in gathering the feedback from the focus groups were:

- Engaging the TrainMoS Stakeholders Networks in the consultation, coordination and adaptation of the academic program to the market demands.

- Time constraints and language barriers were considered an important issue, considering the limited availability of professionals and the number of countries participating.

- Dealing with the need to classify the students according to their level (postgraduate and professionals) and their area of expertise.

- Establishing effective assessment techniques for monitoring student performance and attendance.

- The continuation of the performed educational modules and possible integration in existing degree courses that will promote the maritime and intermodal transport.

- The need to develop the content of a modular MSc/postgraduate diploma/certificate/continuing professional development (CPD) programme with a number of modules, and the elaboration of an accreditation process following the European Credit Transfer and Accumulation System (ECTS) system and the International Convention on Standards of Training, Certification and Watchkeeping for Seafarers of International Maritime Organization (IMO).

- The usage, update and extension of the material and mailing list that was already set up in the previous TrainMoS project, taking into account the new topics indicated from the stakeholders.

Consequently, the focus group meetings revealed that the main challenges discussed in the pertinent literature are common in the maritime industry. In reliance on the feedback from the stakeholders and considering the attractiveness of the various topics to potential students and professionals, five main topics were selected covering (a) alternative fuels and technologies; (b) logistic issues; (c) damage control training; (e) evacuation and crisis management operations; and (f) maritime sustainability and energy savings.

Taking into consideration each group's skills and expertise, as well as their availability, two different streams of courses were prepared with respect to the aforementioned topics (Fig. 2). The first was designed for professionals who require more blended training courses that focus on the existing regulations and their application, whilst the latter was addressing the needs of postgraduate students for a deeper understanding of the maritime industry issues. Both of them aimed to cover topics which are not discussed in traditional educational schemes and provided the experience that is required to improve the skills of each group of learners. A university or a private entity was selected 


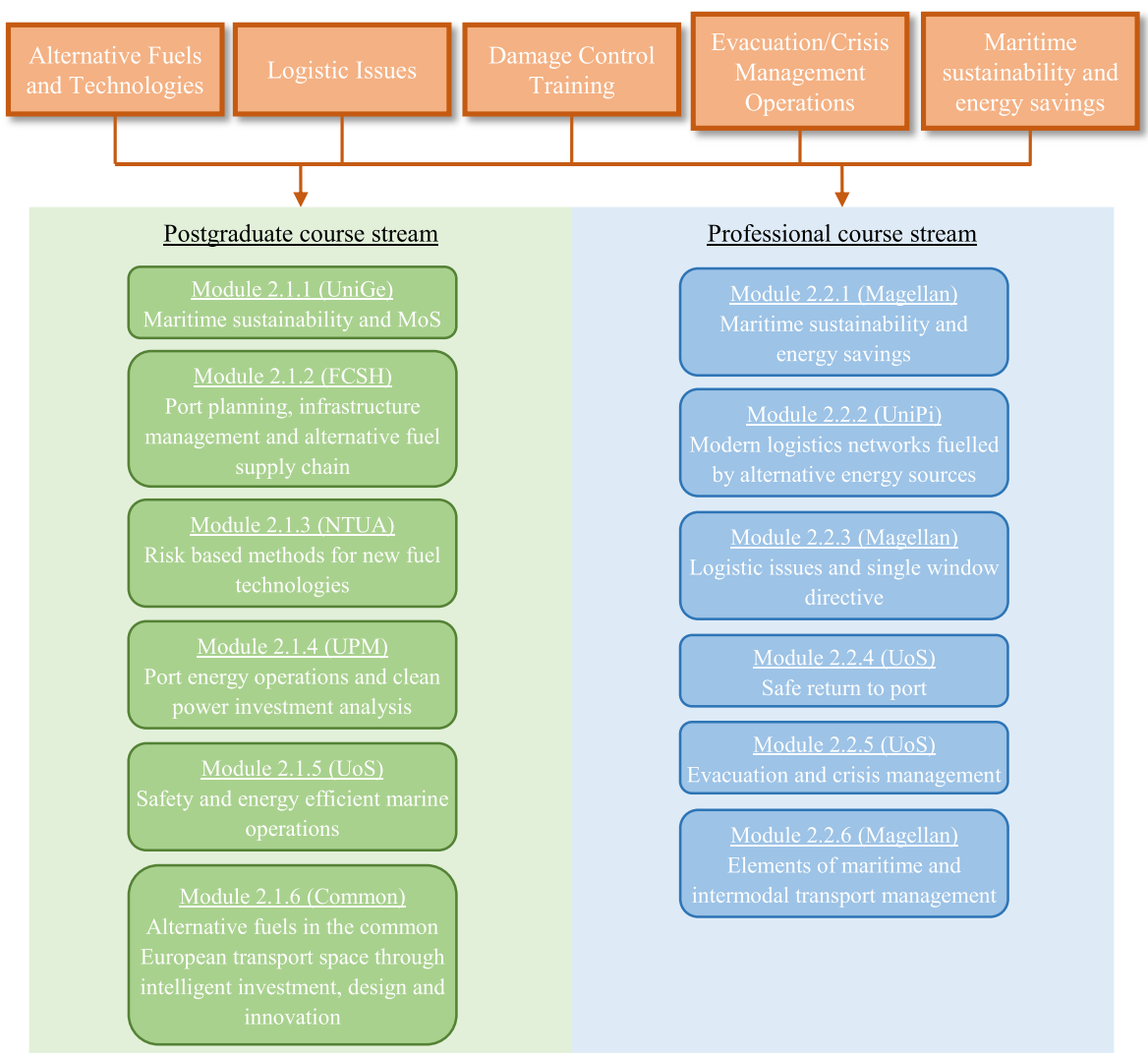

Fig. 2 Delivered courses in TrainMoS II project

from the project's partners to be responsible for the organisation and the material of each module, except of the last module in the postgraduate course stream, whose organisation was shared between the participating universities. The applied approach aligned with the suggestion by Shulman (2005), regarding the different pedagogies that should be followed for professionals with different interests and skills than students. A detailed description of the modules' syllabi is available online through a free registration on the On the MoSway platform (www.onthemosway.eu), including material and videos from the performed courses (On the MoSway portal 2017).

The format of the postgraduate student modules was developed utilising the ECTS accreditation scheme. It was structured in a series of lectures, visits, tutorials, exercises and final assessment in the form of written exams that were required for the successful completion of each module. The structure of the professional modules followed the postgraduate modules, with major differences to the academic level of the covered material and the duration of the module. Each consortium partner was responsible for a specific module, depending on its expertise, delivering in-classroom and streaming live the training modules to students from five different countries using the Spontania LMS (ClearOne 2017). During the modular programme design, it was agreed that the admitted students should have a university degree or any other equivalent academic credentials. 
The distance learning platform was a valuable tool for the successful delivery of the courses. The students at the country, in which the module was delivered, attended inclassroom delivery, while the students from the rest of the countries participated actively online using Spontania LMS. In addition, the provided lectures were recorded, allowing future reference from the students and enhancing the acquired knowledge for future applications through the On the MoSway Portal and the Learning Management Systems (On the MoSway portal 2017; ClearOne 2017). This approach, according to Simonson et al. (2014) taxonomy, allowed the delivery of both in ST-DP and DT-DP.

The quality of the training modules was proven by their accreditation by an international professional body. Considering that TrainMoS II covered two different groups of recipients (PG students and professionals), efforts were made to design a hypothesis of the MSc programme for PG students with the potential to provide CPD certificates to professionals who completed successfully individual modules. A multilateral cooperation agreement was signed among the participating universities covering the credit recognition, whilst the policy and regulatory frameworks at the national level were tracked. Additionally, the universities from each country prepared documents for the accreditation of higher educational programmes for professional engineering competence.

\subsubsection{OTMW-N project}

The educational programme that was designed for the OTMW-N followed a similar approach to the TrainMoS II project. Particularly, an informal network was created for the follow-up of training actions in the future. The main objective of the network was to perform a detailed analysis of the current processes that should be performed from the personnel; to reveal the challenges in the existing procedures; and to suggest the new actions that should be taken into account during training. The main outcomes of the established network focused to bridge the different perspectives on the use of LNG for bunkering.

The training modules were based on current demands in the industry in this case too. Subjects and content were defined and tested to meet the market demands, as they were described by the major stakeholders through meetings that were performed during the course design and before the final delivery of the modules. Carter's (1985) taxonomy of objectives for professional education and the feedback received from the market and the current employees were taken onboard. This was used to finalise the modules' curriculum. Each partner contributed to the training programme according to its specialisation and experience to ensure the development of a competitive package of training modules, combining theoretical knowledge with simulation activities. The generated modules of the OTMW-N project are presented in Fig. 3. A wide number of important activities were covered by the OTMW-N project, including:

- A set of professional trainings and vocational education activities in four European countries and in different cities, mainly in ports or even on board.

- A number of cross-fertilisation on-site dedicated visits related to LNG bunkering best practice and an opportunity to 'train the trainer'.

- An enlarged LNG content of a professional portal including an application available on mobile phones and tablet.

- A set of activities in professional social media. 


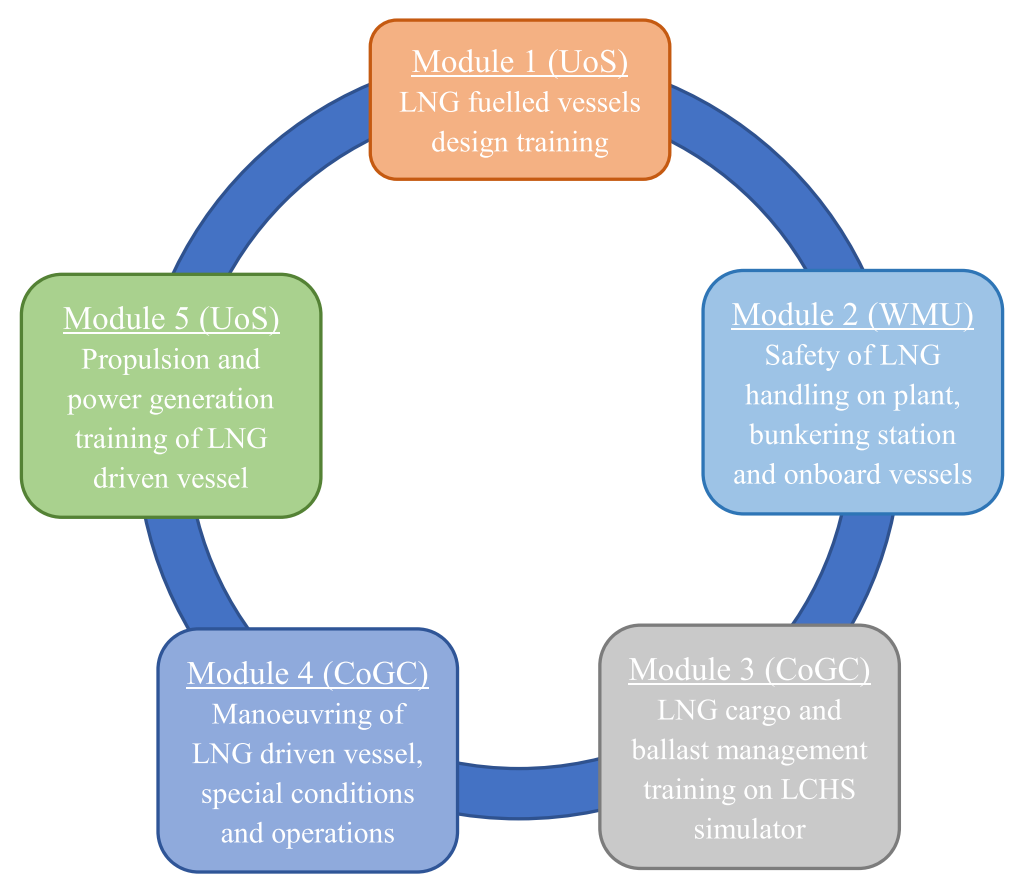

Fig. 3 Delivered modules in OTMW-N project

- A set of clustering activities engaging a large number of stakeholders and liaising with a number of LNG projects.

- A conference on the introduction of LNG as a long terms strategy for supporting the greening of TEN-T and of MoS as its maritime dimension.

- The creation of a formal association of stakeholders for the promotion of MoS in Europe.

The significance of distance learning was taken into account during the planning of the OTMW-N project. The Spontania videoconference tool gave the opportunity of gathering the best lecturers and specialists relative to the project's topic at the same 'location', even if they were located in different countries, performing blended learning courses to the participants of the programme. Concerning the future development and the feasibility of the formal association that was formed within the project, a memorandum of understanding was signed among the OTMW-N partners confirming their wish to cooperate in the promotion of the courses, the development of new material, the update of the onthemosway.eu platform and the evolution of the network itself.

\subsubsection{Programme certification}

The idea of the industry involvement to the educational programmes provided by the academia received an extremely positive feedback from the maritime industry. More than 300 stakeholders from public and private entities in more than 6 countries were involved in both projects, with valuable contribution to the module design and content 
selection. At the same time, the stakeholders were introduced to the 'On the MoSway' online platform for covering their future training needs and posting relevant job vacancies in case they may arise.

At the end of these projects, a certificate of successful attendance was given to each participant as a qualification for the acquired knowledge, accredited by the Institute of Marine Engineering, Science and Technology (IMarEST, www.imarest.org), a highly respectable international professional organisation. In terms of accreditation, the framework of a European MSc programme in maritime studies, with the participation of many universities from different countries was defined and prepared. Due to the limited time constraints and the misalignment of the academic year with the project's planning and delivery, the completion of the MSc programme was not feasible. However, the prepared modules' syllabi have great potential for exploitation in the near future.

\subsection{Students participation and feedback}

Considering that both 'TrainMoS II' and 'OTMW-N' projects focused on the education and training of the individuals who already work or intend to work in the maritime industry, the most important outcome of this project is the participants' satisfaction. The students' feedback can be considered as the real metric for the evaluation of the choices made during the design of the modular educational programmes. In the established programmes, a number of more than 70 students and 85 professionals attended successfully to the courses, either by physical presence or using the Spontania software. The blended learning mode of both in-campus (local) and off-campus (distance) students is depicted in Fig. 4. Though the local students' percentage is higher than the respective distance learning percent, the fact that almost one out of three students was using the online platform to follow the educational programmes, proved the high potential of the ICT tools and their flexibility to deliver educational programmes. The results indicate also that the appeal of ICT for educational and training purposes to the students and professionals is increasing continuously. The students' preference to attend training programmes using ICT is supported also by the outcomes of the postgraduate students' participation in the modules (Fig. 5).

The reduced number of unsuccessful attendance (dropouts) noticed during the courses can be justified by assessing the students' feedback. At the end of each module, a questionnaire was shared to the students to evaluate in detail the structure and the curriculum of each module, and to express their satisfaction level for the support that

a)

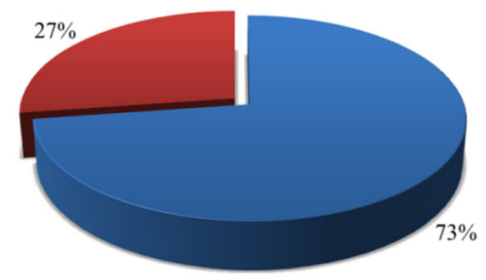

Local Students Distance Learning Students b)

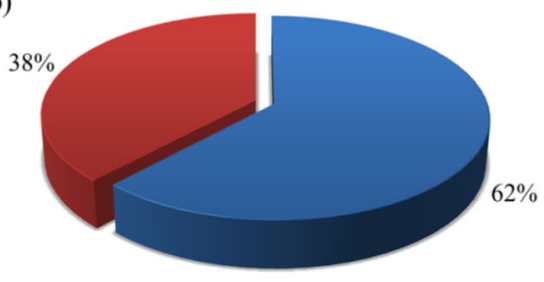

- Local Students Distance Learning Students

Fig. 4 Distribution of a professional students in TrainMoS II project and $\mathbf{b}$ students in OTMW-N project 


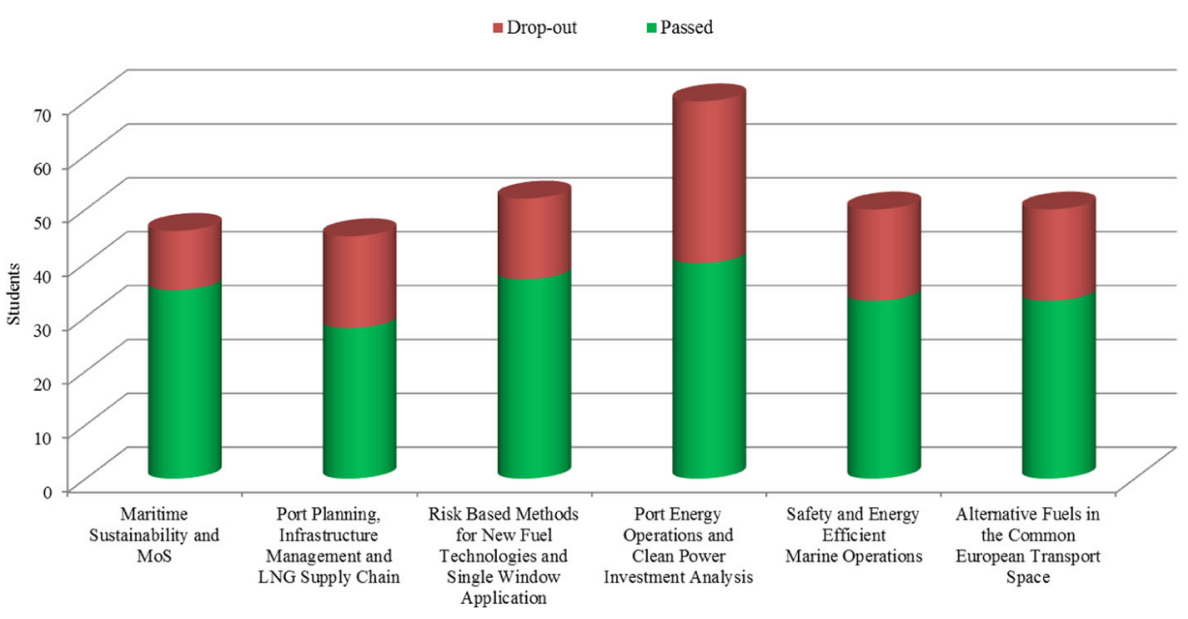

Fig. 5 Postgraduate students' participation in TrainMoS II project modules

they had during the courses. As it is presented in Fig. 6, the overall feedback from the students was quite satisfactory. Almost half of the students were very or extremely satisfied with the material and the structure of the delivered courses, with the highest percentage of satisfaction to be noticed in the 'Maritime Sustainability and MoS' module, due to the presented material in this course. Apart of this module, the 'Alternative Fuels in the Common European Transport Space' and the 'Safety and Energy Efficient Marine Operations' modules scored high in the module structure and material, demonstrating the interest of the participants to improve their knowledge on the new technologies and the future amendments to the corresponding regulations.

The overall organisation and support of the modules received the highest rating, which was very pleasing given the technological and organisational challenges of running and streaming live modules across the whole of Europe. The majority of the students found the courses quite helpful. The only drawback reported was the additional time that was requested for better 'digestion' of the content as the assessment was right after the completion of the lectures. The results from the students' questionnaire assessment reveal also that they found more interesting the courses related to new technologies, the maritime sustainability and the safety during marine operations.

\subsection{Knowledge platform}

An important outcome of the projects was the further development of the IT platform developed by Circle S.p.A. It was based on an earlier more primitive version of it, whilst a network was created for the follow-up of training actions in the future. The statistics of the platform during the project's duration (from May 2014 to December 2015) are presented in Table 2. The produced material included more than $1000 \mathrm{~h}$ of video presentations of the training sessions and more than 12,000 uploaded files that contain lecture notes and additional useful material (e.g. regulations, case studies, examples, presentations etc.). The huge amount of data from the training modules (over $150 \mathrm{~GB}$ ) was available online with open access to all registered students (On the MoSway portal 2017). Simultaneously with the established knowledge platform, an 


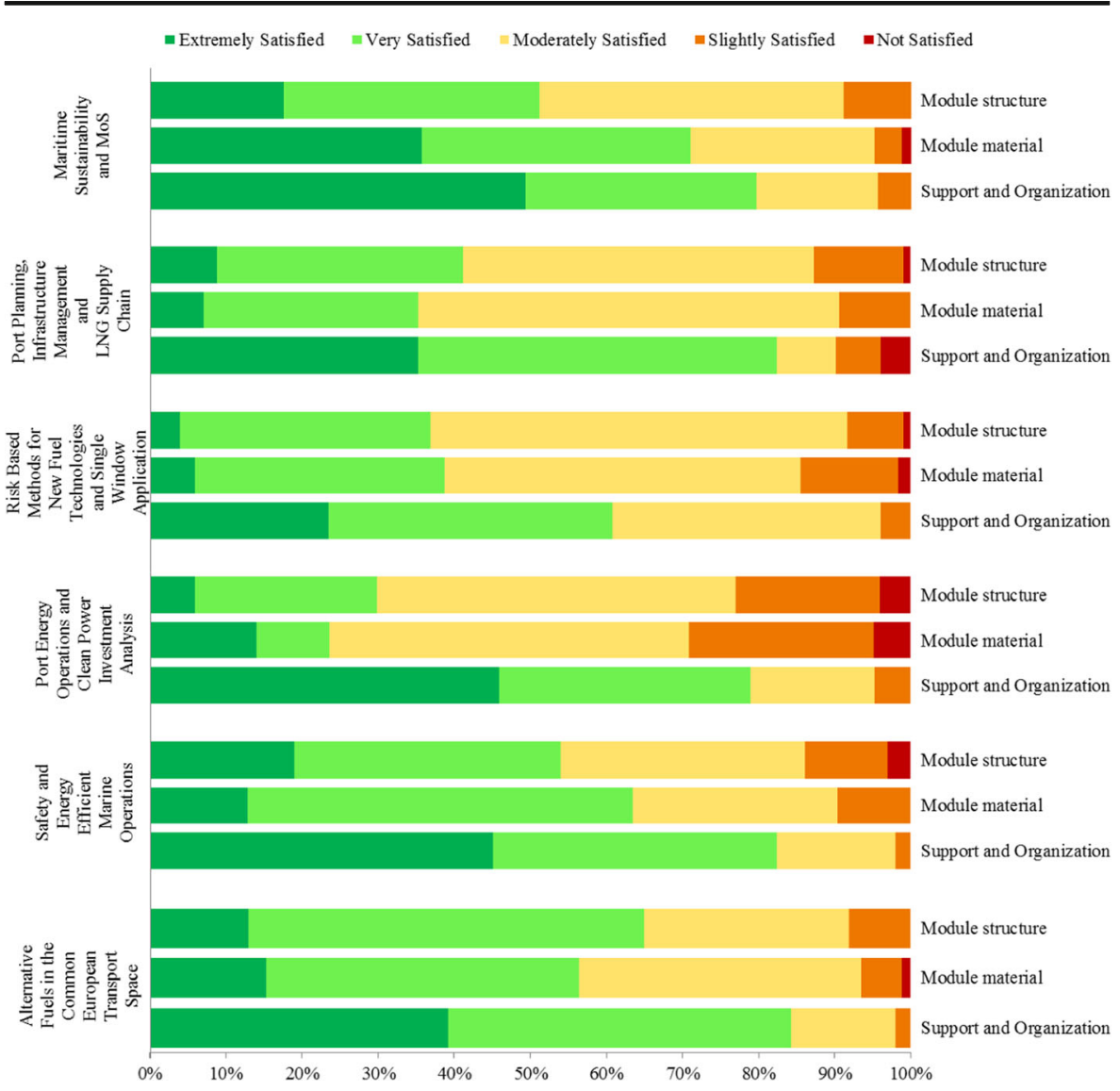

Fig. 6 Postgraduate students' feedback in TrainMoS II project modules

Android-based application was developed under the title 'On the MoSway Training Center'. Through this application, the users were able to reach the delivered courses' description, the contact information and the training materials produced within the courses, though the project's end. The developed application still offers access to various maritime educational modules to the users through their mobile devices.

Table 2 onthemosway.eu portal statistics data (May 2014-Dec 2015)

Site Indices

\begin{tabular}{ll}
\hline Visits & 20,235 \\
Unique visitors & 13,185 \\
Page views & 53,342 \\
Average time spent on the site & $\sim 3 \mathrm{~min}$ \\
Newsletter total subscribers & 1133
\end{tabular}

Geographical coverage with most visits

Italy, UK, Greece, Spain, USA, Portugal, Germany, Belgium, France, Netherlands 
The 'On the MoSway' portal can be considered as a multichannel platform that is open to companies and professionals and it aims to deliver and to store useful knowledge and specialised information regarding the MoS development in Europe with the support of the European Union. The great success of the 'On the MoSway' portal is that it can be accessed online, discovering the growth of the platform and its continuous update with news, research projects and a plethora of topics correlated to the maritime industry. Inspired by the Blue Economy principles, a specific section was introduced in the portal during the TrainMoS II project, dedicated to match the job market demand and the supply of training and provided services. As such, the "On the MoSway" platform attempted to match the maritime market needs with the training provision and the development of new or enrichment of the existing online platform with new material and knowledge for both professionals and students (On the MoSway portal 2017). The online platform allowed better communication between the students and the lecturers, improving the dissemination of the training programs and the overall experience for both of them. The development and extension of Spontania and Fractalis LMS ICT ensured the sustainability of the modules, the flexibility of the delivered courses and the availability of the material for future applications. Particularly, the application of the Spontania tool increased the meeting capacity of the online sessions and improved the quality of the teaching through the instant messaging tool. The Fractalis LMS ICT, with the integrated collaborative tools, improved the management of the online courses.

\section{Conclusions}

VET programmes are considered as one of the most constructive ways to the Blue Economy. The balance between industry demands and society needs for a sustainable economy is achievable only through the knowledge exchange and sharing. In particular, maritime industry is a dynamic market with high turnover, many technological evolutions, continuous policy amendments and enormous size of information and knowledge. The TrainMoS II and OTMW-N projects, presented within this paper, had as a main target to focus on the foundation of European maritime educational programmes, covering all the levels of a classical educational and training system, from students till lecturers and from professionals till trainers.

The main contribution of these projects to the maritime education was the development of custom-made courses that reflect the market needs. The provided courses from European Universities with great experience on topics with high demand in maritime industry offered the opportunity to the students to learn about the existing policy framework and application of new technologies in shipping. Also, the flexibility on the design of the modules improved the training programme's impact, maximising the knowledge that could be obtained from the students.

During these projects, educational material and video sessions were produced and recorded, offering insight to maritime industry issues that were not covered from the existing educational programmes. Through these modules, a network of maritime stakeholders was traced and links between industry and educational institutes were established, whilst early signs for the future development of a European educational programme in shipping and maritime infrastructures were set. The dynamic participation of students, stakeholders and universities in these projects proved the interest of all 
actors to the deployment of additional educational programmes that will be directly connected with industry and society, improving the technology research and growth in fields of maritime industry with limited knowledge and competitiveness and enhancing the safety within shipping operations and shipbuilding.

Connecting the participants' feedback with the development of the online tools, the most important outcome of these projects is the high interest of the individuals to the introduction of visual means to the classic educational schemes. The combination of the blended learning by using ICT and the development of courses that reflect the actual needs of the industry can be considered as a successful recipe that increases the interest of the students to engage and participate. Moreover, the selection of a cognitive and behaviourist orientation mix to the maritime education, supported by modular programmes and training certification, increased the participation and reduced the dropout of the programme participants.

Although the produced material and platforms within these projects constituted the first steps to the success of the Global Project, further steps are required. The main aspects for any future maritime educational programme require the continuous update of the educational material, the stronger connection between education and job market and the active communication among research, regulatory bodies and industrial partners. Moreover, the definition of a commonly accepted educational framework and its adaptation from the European countries will assist in the knowledge exchange in Europe. However, sufficient funding of such actions is required, inviting new players and maintaining the efficiency of educational programmes in society.

Acknowledgements The present work was conducted within the European Commission co-financed projects TrainMoS II (2014-2015), Decision no. 2013-EU-21012-S, and On the MOSway Network (2014-2015), contract no. MP/2013/035/ONTHEMOSWAY NETWORK in the framework of the MARCO POLO II Programme (2007-2013). The authors would like to express their gratitude to all the TrainMoS II and OTMW-N Partners for their excellent collaboration and substantial contribution to the successful completion of both projects.

Funding The corresponding author greatly acknowledges the DNV GL and Royal Caribbean Cruises Ltd. sponsorships to the Maritime Safety Research Centre at the University of Strathclyde.

\section{Compliance with ethical standards}

Disclaimer The European Commission and the authors shall not in any way be liable or responsible for the use of any knowledge, information or data of the present paper, or of the consequences thereof. The views expressed in this paper are those of the authors and do not necessary reflect the views and policies of the European Commission, DNVGL and RCCL.

Open Access This article is distributed under the terms of the Creative Commons Attribution 4.0 International License (http://creativecommons.org/licenses/by/4.0/), which permits unrestricted use, distribution, and reproduction in any medium, provided you give appropriate credit to the original author(s) and the source, provide a link to the Creative Commons license, and indicate if changes were made.

\section{References}

Allen IE, Seaman J (2014) Grade change: tracking online education in the United States. Babson Survey Research Group Report 
Bassoppo-Moyo TC (2006) Evaluating e-learning: a font-end, process and posthoc approach. Int J Instr Media 33:7e22

Bloom BS (1956) In: Engelhart MD, Furst EJ, Hill WH, Krathwohl DR (eds) Taxonomy of educational objectives: the classification of educational goals. Handbook 1: Cognitive domain. David McKay, New York

Bruges Communiqué (2010) The Bruges Communiqué on enhanced European Cooperation in Vocational Education and Training for the period 2011-2020, [online] Available at: http://ec.europa. eu/dgs/education_culture/repository/education/policy/vocational-policy/doc/brugescom_en.pdf

Carter R (1985) A taxonomy of objectives for professional education. J Stud High Educ 10(2):135-149

ClearOne (2017) Spontania cloud-based media collaboration. [online] Available at: http://www.clearone. com/products_spontania. Accessed 21 Sep. 2017

Commission of the European Communities (2001) European transport policy for 2010: time to decide. White Paper from the Commission to the European Council, COM (2001) 370 final, Brussels

Commission of the European Communities (2011) Roadmap to a single European transport area-towards a competitive and resource efficient transport system. White paper from the Commission to the European Council, COM (2011) 144 final, Brussels

Conaway RN, Easton SS, Schmidt WV (2005) Strategies for enhancing student interaction and immediacy in online courses. Bus Commun Q 68:23-35

De Oliveira L (2013) Priority project 21 motorways of the sea: annual activity report 2012-2013.Brussels

European Commission (1992) Treaty on European Union (Maastricht text), July 29, 1992, 1992 O.J. C 191/1 [hereinafter Maastricht TEU]

European Commission (2002) Declaration of the European ministers of vocational education and training, and the European Commission, convened in Copenhagen on 29 and 30 November 2002,on enhanced European cooperation in vocational education and training. [hereinafter "The Copenhagen Declaration"]

European Commission (2010a) The Lisbon strategy 2000-2010: an analysis and evaluation of the methods used and results achieved. [online] Available at: http://www.europarl.europa. eu/document/activities/cont/201107/20110718ATT24270/20110718ATT24270EN.pdf. Accessed 14 Dec. 2017

European Commission (2010b) EUROPE 2020: a strategy for smart, sustainable and inclusive growth, COM(2010) 2020. [online] Available at: http://ec.europa.eu/eu2020/pdf/COMPLET\%20EN\%20 BARROSO $\% 20 \% 20 \% 20007 \% 20-\% 20$ Europe\%202020\%20-\%20EN\%20version.pdf. Accessed 14 Dec. 2017

European Commission (2010c) Directive 2010/65/EU of the European Parliament and the Council of 20 October 2010 on reporting formalities for ships arriving in and/or departing from ports of the Member States and repealing Directive 2002/6/EC, OJ L 283, 29.10.2010, p. 1

European Commission (2011) Transport 2050: Commission outlines ambitious plan to increase mobility and reduce emissions. [online] Available at: http://europa.eu/rapid/press-release_IP-11-372_en.htm. Accessed 13 Sep. 2015

European Commission (2013) TrainMoS 2011-EU-21004-S Project Description. [online] Available at: http://ec.europa.eu/inea/sites/inea/files/download/project_fiches/multi_country/fichenew_2011eu21004s final_2.pdf. Accessed 5 Oct. 2015

European Commission (2014) Decision of the Innovation and Networks Executive Agency (INEA) establishing 27 projects eligible under the second "Marco Polo" programme for receiving EU financial aid in the framework of Commission Implementing Decision C (2013) 1489 and the 2013 Call for Proposals launched on 26 March 2013. [online] Available at: https:/ec.europa.eu/transport/marcopolo/files/calls/docs/2013 /call2013-award-decision.pdf. Accessed 07 Dec. 2018

European Commission (2017) TEN-T Priority Project 21: Motorways of the Sea - Project Description. [online] Available at: https://ec.europa.eu/inea/en/ten-t/ten-t-projects/projects-by-priority-project/priority-project-21. Accessed 13 Sep. 2017

European Commission (2018a) The European Higher Education Area in 2018 - Bologna Process Implementation Report. EACEA, Education and Youth Policy Analysis. [online] Available at: https:/eacea.ec.europa.eu/national-policies/eurydice/sites/eurydice/files/bologna_internet_0.pdf. Accessed 18 Jul. 2018

European Commission (2018b) TrainMoS II 2013-EU-21012-S Project Description. [online] Available at: https:/ec.europa.eu/inea/sites/inea/files/2013-eu-21012-s_final.pdf. Accessed 7 Dec. 2018

Fischman GE (2000) Imagining teachers: rethinking gender dynamics in teacher education. Rowman and Littlefield, Lanham

Garrison DR, Kanuka H (2004) Blended learning: uncovering its transformative potential in higher education. Internet High Educ 7(2):95-105. https://doi.org/10.1016/j.iheduc.2004.02.001 
Grewal D, Haugstetter H (2007) Capturing and sharing knowledge in supply chains in the maritime transport sector: critical issues. Marit Policy Manag 34(2):169-183

Haggis T (2009) Pedagogies for diversity: retaining critical challenge amidst fears of 'dumbing down. Stud High Educ 31(5):521-535. https://doi.org/10.1080/03075070600922709

HEA (2014) Framework for partnership in learning and teaching in Higher Educations. [online] Available at: https://www.heacademy.ac.uk/system/files/resources/hea_framework_for_partnership_in_learning_and_ teaching.pdf. Accessed 18 Jul. 2018

IBCVET (2017) International European Benchmarking on CVET for Blue jobs-skills-economy. [online] Available at: http://www.ibcvet.eu/. Accessed 13 Sep. 2017

Jensen JJ, Andersen IMV, Nielsen UD, Andersen P (2014) The new maritime engineering education at the Technical University of Denmark. In: Proceedings of the 15th IAMU annual general assembly: looking ahead - innovation in maritime education, training and research. 353-359. International Association of Maritime Universities

Kebritchi M, Lipschuetz A, Santiague L (2017) Issues and challenges for teaching successful online courses in higher education. J Educ Technol Syst 46(1):4-29

Krathwohl DR (2002) A revision of Bloom's taxonomy: an overview. J Theory Into Pract 41(4) Autumn 2002

Krathwohl DR, Bloom BS, Masia BB (1964) Taxonomy of educational objectives: the classification of educational goals. Handbook II: the affective domain. David McKay, New York

Limperos AM, Buckner MM, Kaufmann R, Frisby BN (2015) Online teaching and technological affordances: an experimental investigation into the impact of modality and clarity on perceived and actual learning. Comput Educ 83:1-9

Merriam S, Caffarella (1991, 1998) Learning in adulthood. A comprehensive guide. Jossey-Bass, San Francisco, p 528 pages

Middendorf J, Pace D (2004) Decoding the disciplines: a model for helping students learn disciplinary ways of thinking. In: New directions for teaching and learning: no. 98. Decoding the disciplines: helping students learn disciplinary ways of thinking, edited by David Pace and Joan Middendorf. 1-12. San Francisco: Jossey-Bass

Ministerial Declaration (1998) Sorbonne Joint Declaration - Joint Declaration on harmonisation of the architecture of the European higher education system by the four Ministers in charge for France, Germany, Italy and the United Kingdom. France, Paris, the Sorbonne, May 25. [online] Available at: http://www.ehea.info/media.ehea.info/file/1998_Sorbonne/61/2/1998_Sorbonne_Declaration_ English_552612.pdf. Accessed 18 Jul. 2018

Ministerial Declaration (1999) The Bologna Declaration - Joint Declaration of the European Ministers of Education. Italy, Bologna, June 19. [online] Available at: https://www.eurashe.eu/library/modernisingphe/Bologna_1999_Bologna-Declaration.pdf. Accessed 18 Jul. 2018

Moore MG, Kearsley G (2012) Distance education: a systems view of online learning, 3rd edn. Wadsworth Cengage Learning ISBN 978-1-111-52099-1

National Institutes on Post-Secondary Education (2000) Emerging research findings: connections between education and work

Ng AKY, Koo AC, Ho WCJ (2009) The motivations and added values of embarking on postgraduate professional education: evidences from the maritime industry. Transp Policy 16(5):251-258

OECD (2013) A skills beyond school commentary on Scotland. OECD reviews of vocational education and training. OECD Publishing

OECD (2014) Skills beyond school: synthesis report, OECD reviews of vocational education and training. OECD Publishing

On the MoSway portal (2017) [online] Available at: http://www.onthemosway.eu/. Accessed 4 Dec. 2018

Porter WW, Graham CR, Spring KA, Welch KR (2014) Blended learning in higher education: institutional adoption and implementation. Comput Educ 75:185-195

Romiszowski AJ (1981) Designing instructional systems: decision making in course planning and curriculum design. Kogan Page

Ross WD, Brown L (2009) Aristotle-The Nicomachean ethics. Oxford University Press, Oxford

Shulman LS (2005) Signature pedagogies in the professions. Dædalus 134(3):52-59. https://oi.org/10.1162 $/ 0011526054622015$

Simons M (2008) Learning as investment: notes on governmentality and biopolitics. Educ Philos Theory 38(4):524-540. https://doi.org/10.1111/j.1469-5812.2006.00209.x

Simonson M, Smaldino S, Zvacek SM (2014) Teaching and learning at a distance: foundations of distance education, 6th edn. Information Age Publishing ISBN 978-1-62396-798-7

Simpson B (2015) Motorways of the sea work plan of the European coordinator 
Tobias S (1992) Disciplinary cultures and general education: what can we learn from our learners? Teach Excell 4:6. 1-6. 3

Vermunt JD (2007) The power of teaching -learning environments to influence student learning. In: Entwistle N, Tomlinson P. BJEP Monograph Series II-Student Learning and University Teaching 4:6, 73-90

Publisher's note Springer Nature remains neutral with regard to jurisdictional claims in published maps and institutional affiliations.

\section{Affiliations}

\section{Evangelos Boulougouris ${ }^{1}$ - Panagiotis Mizythras ${ }^{1} \cdot$ Leonidas Chrysinas $^{2}$.} Georgios Vavourakis ${ }^{2} \cdot$ Gerasimos Theotokatos $^{1}$ - Murat Aymelek ${ }^{3,4}$. Ismail Kurt ${ }^{3}$

1 Maritime Safety Research Centre, Department Of Naval Architecture, Ocean \& Marine Engineering, University of Strathclyde, 100 Montrose St, Glasgow G4 0LZ, UK

2 Department of Naval Architecture, Ocean \& Marine Engineering, University of Strathclyde, 100 Montrose St, Glasgow G4 0LZ, UK

3 Faculty of Naval Architecture and Maritime, Izmir Katip Celebi University, Cigli Main Campus, Izmir, Turkey

4 Socio-Economic Marine Research Unit, Whitaker Institute for Innovation and Societal Change, National University of Ireland Galway, Galway, Ireland 